\title{
TATA KELOLA MANAJEMEN ASET TI MENGGUNAKAN FRAMEWORK COBIT 5 DAN ITAM
}

\author{
Theresia Meiriati ${ }^{1}$, Anggi Srimurdianti Sukamto ${ }^{2}$, Nurul Mutiah ${ }^{3}$ \\ [1],[3] Jurusan Sistem Informasi ${ }^{[2]}$ Teknik Informatika; Fakultas MIPA Universitas Tanjungpura \\ Jalan Prof.Dr. H. Hadari Nawawi, Pontianak \\ Telp / Fax: (0561) 577963 \\ E-mail: 'theresiameiriati07@gmail.com, 2anggidianti@gmail.com, ${ }^{3}$ nurul@sisfo.untan.ac.id
}

\begin{abstract}
Abstrak
Teknologi Informasi (TI) merupakan aset yang sangat dibutuhkan oleh suatu perusahaan atau instansi. Salah satu instansi yang melakukan tata kelola TI adalah Dinas Komunikasi dan Informatika (Diskominfo) Kota Sintang. TI memiliki peran penting dalam mendukung pencapaian suatu visi, misi dan tujuan organisasi. IT Asset Management (ITAM) merupakan seperangkat praktik bisnis atau framework yang digunakan untuk melakukan manajemen aset TI terhadap keseluruhan aset yang ada pada suatu instansi. COBIT 5 (Control Objective for Information and related Technology) merupakan kerangka kerja yang di terbitkan oleh ISACA. Sedangkan COBIT PAM (Process Assessment Model) merupakan model yang berisi kerangka dasar yang memberikan panduan dalam menilai dan mengukur tingkat kematangan yang berkaitan dengan teknologi informasi khususnya pada proses manajemen aset TI. Hasil dari proses assesment COBIT 5 terhadap manajemen aset TI menyatakan bahwa proses Manajemen aset TI pada Diskominfo menghasilkan bahwa proses request dan deploy aset masih berada pada level 0. Proses procurement, receive, monitor/maintain, retire/reuse dan disposal masih berada pada level 1. Berdasarkan hasil yang diperoleh maka diberikan rekomendasi perbaikan yang dapat digunakan untuk meningkatkan level kematangan sesuai dengan tingkat kematangan yang diharapkan.
\end{abstract}

\section{PENDAHULUAN}

Teknologi Informasi memiliki peran yang sangat penting dalam suatu perusahaan atau lembaga instansi. Untuk menjaga agar teknologi informasi dapat memberikan nilai tambah bagi perusahaan atau lembaga maka perlu dilakukan suatu tata kelola teknologi informasi yang baik. Tata Kelola TI merupakan tanggung jawab pimpinan direktur dan manajemen eksekutif yang merupakan bagian integral dari tata kelola perusahaan dan terdiri dari kepemimpinan, struktur organisasi serta proses-proses yang menjamin bahwa organisasi TI dapat mendukung dan memperluas sasaran serta strategi organisasi [1].

Manajemen aset TI sangat penting sebagai bahan strategis untuk tata kelola TI perusahaan. IT Asset Management (ITAM) adalah seperangkat praktik bisnis yang menggabungkan asset-aset TI di seluruh unit bisnis dalam suatu organisasi [2].

COBIT 5 (Control Objective for
Information and Related Technology) sebagai kerangka tata kelola dan audit TI, COBIT 5 merupakan versi terbaru yang diluncurkan oleh ISACA yang merupakan lembaga yang menangani bidang tata kelola teknologi informasi. COBIT 5 berperan dalam membantu organisasi untuk mensinambungkan antara manfaat teknologi informasi, penggunaan sumber daya dan pengelolaan resiko [3].

Keuntungan penerapan ITAM dan COBIT 5 adalah memberikan strategi untuk menjaga biaya TI agar tetap rendah dan mengelola risiko yang terkait dengan menejemen aset TI, untuk mencapai nilai maksimum pemangku kepentingan dari investasi TI.

Dinas Komunikasi dan Informatika (Diskominfo) Kota Sintang didirikan pada tahun 2017, dengan hadirnya Diskominfo maka diharapkan dapat meningkatkan kinerja pemerintah Kota Sintang dalam hal meningkatkan hubungan antara pemerintah 
dengan masyarakat maupun unit bisnis.

Berdasarkan permasalahan maka dilakukan penelitian ini untuk mengukur tingkat kapabilitas dari manajemen aset TI dengan menggunakan framework COBIT 5 dan ITAM. Hasil dari Penelitian ini instansi akan mendapatkan ukuran dari tingkat kapabilitas manajemen aset TI berdasarkan praktik dari ITAM dan framework COBIT 5 serta rekomendasi perbaikan yang dapat ditindak lanjuti dalam instansi untuk pengembangan tata kelola teknologi informasi kedepannya agar lebih baik lagi dan dapat mendukung perkembangan Diskominfo Kota Sintang.

\section{LANDASAN TEORI}

Didalam landasan teori terdapat dasar teori yang digunakan dalam penelitian dan tinjauan pustaka untuk menjadi pembanding dengan topik penelitian saat ini. Adapun dasar teori dan tinjauan pustaka yakni sebagai berikut:

\subsection{Dasar Teori \\ 2.1.1 Tata Kelola TI}

Tata kelola TI adalah pertanggungjawaban dewan direksi dan manajemen eksekutif. Hal ini, merupakan bagian yang terintegrasi dengan tata kelola perusahaan dan berisi kepemimpinan dan struktur serta proses organisasi yang menjamin bahwa organisasi TI mengandung dan mendukung strategi serta tujuan bisnis [4].

\subsubsection{COBIT 5 (Control Objective for Information and Related Technology) \\ COBIT 5 adalah sebuah kerangka} menyeluruh yang dapat membantu suatu organisasi dalam mencapai tujuannya untuk tata kelola dan manajemen perusahaan [5].

COBIT 5 membagi dua area yakni governance dan management. Pada area governance terdapat satu domain yakni EDM. Sedangkan pada area management terdapat empat domain yakni APO, BAI, DSS dan MEA.

\subsubsection{COBIT PAM (Process Assesment Model)}

Model penilaian pada COBIT 5 berbeda dengan penilaian pada COBIT 4.1. Produk dari COBIT 5 termasuk dalam process capability model yang proses penilaiannya menggunakan ISO/IEC 15504 [6]. Adapun kapabilitas proses dijelaskan dalam atribut proses yang telah terkelompokan kedalam capability level seperti pada tabel1.

Tabel 1. Capability Level PAM

\begin{tabular}{|l|l|}
\hline \multicolumn{2}{|c|}{ ISO 15504 Process } \\
\hline \multicolumn{1}{|c|}{ Capability Level } & \multicolumn{1}{c|}{ Attribute Process } \\
\hline 5 Optimizing & $\begin{array}{l}\text { PA 5.1 Process Innovation } \\
\text { PA 5.2 Process Optimization }\end{array}$ \\
\hline 4 Predicteble & $\begin{array}{l}\text { PA 4.1 Process } \\
\text { Measurement PA 4.2 Process } \\
\text { Control }\end{array}$ \\
\hline 3 Established & $\begin{array}{l}\text { PA 3.1 Process Definition } \\
\text { PA 3.2 Process Deployment }\end{array}$ \\
\hline & $\begin{array}{l}\text { PA 2.1 } \\
\text { Performance Management PA } \\
2.2 \text { Work Product } \\
\text { 2 Managed }\end{array}$ \\
\hline 1 Performed & PA 1.1 Process Performnce \\
\hline 0 Incomplete & \\
\hline
\end{tabular}

Model penilaian proses berdasarkan Framework COBIT 5 menggunakan pendekatan baru yang berbasis pada International Organization for Standardization (ISO) / International Electrotechnical Commission (IEC) 15504, yakni Process Assessment Model (PAM) [6].

Untuk menilai Level 0 dan 1 dapat dilihat dari BP (Base Practice) yakni aktifitas yang dilakukan organisasi dan WP (Work Product) merupakan output atau dokumen yang dihasilkan organisasi.

Untuk mencapai level berikutnya skala penilaian harus mencapai $100 \%$. Sedangkan level 2,3,4, dan 5 didapat dari indikator atributnya yaitu GP (Generic Practice), dan GWP (Generic Work Product) [6].

Adapun model dasar untuk penilaian kemampuan proses TI suatu perusahaan terhadap framework COBIT 5 dapat dilihat pada gambar 1. 


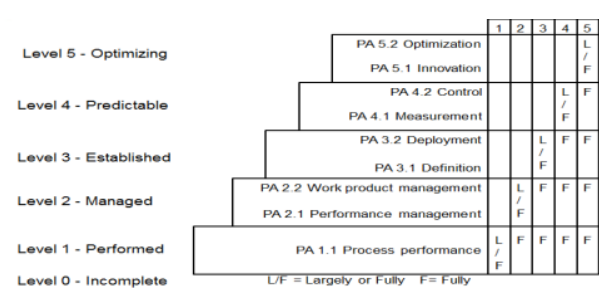

Gambar 1. Penilaian Capability Level

Penilaian pada COBIT PAM memiliki atribut yang jelas dan dapat dipertahankan.Skala penilaian digunakan setelah memperoleh hasil dari analisa tingkat kapabilitas. Setiap atribut dinilai menggunakan standar skala penilaian yang dijelaskan dalam standar ISO/IEC 15504 [6].

Skala pengukuran terdiri dari

1. $\mathrm{N}$ (Not Achived) - Tidak dicapai (0 - 15\% pencapaian).

2. P (Partially Achived) - Sebagian mencapai (15\% - 50\% pencapaian).

3. L (Largely Achived) - Sebagian besar mencapai (50\% - 85\% pencapaian)

4. F (Fully) - Sepenuhnya mencapai (85\% $100 \%$ pencapaian).

\subsubsection{RACI Chart}

Diagram RACI adalah matriks untuk seluruh aktivitas atau otorisasi keputusan yang harus diambil dalam suatu organisasi yang dikaitkan dengan seluruh pihak atau posisi yang terlibat.Diagram RACI berisi sejumlah struktur organisasi yang menggambarkan peran dan tanggung jawab. RACI merupakan singkatandariResponsible (R), Accountable (A), Consulted(C), dan Informed (I) [6].

\subsubsection{Analisis Kekuatan dan Kelemahan}

Menurut Philip Kotler (2002), pengertian analisis SWOT adalah evaluasi terhadap semua kekuatan (strenghts), kelemahan (weeknesses), peluang (opportunity), dan ancaman (threats) yang terdapat pada individu atau organisasi.Analisis SWOT memiliki fungsi untukmendapatkan informasi dari analisis situasi dan memisahkannya dalam pokok persoalan internal (kekuatan dan kelemahan) dan pokok persoalan eksternal (peluang dan ancaman). Namun didalam penelitian ini hanya dilakukan analisis kekuatan dan kelemahan atau yang menyangkut proses internal saja. Analisiskekuatan dan kelemahan digunakan untuk memberi rekomendasi perbaikan untuk capability level [7].

\subsubsection{Analisis GAP}

Untuk menilai tingkat kematangan saat ini (as-is), dilakukan penilaian terhadap masing- masing aktivitas [5]. Tingkat kematangan atribut diperoleh dari perhitungan kuesioner seperti pada persamaan nilai 1

Tingkat Kematangan Atribut = (1)

Keterangan:

$\mathrm{a}=$ Jumlah jawaban (ya)

$\mathrm{n}=$ Jumlah pertanyaan

Setelah menilai tingkat kematangan saat ini (as-is) selanjutnya menilai tingkat kematangan yang diharapkan (to-be). Penilaian tingkat kematangan yang diharapkan (to-be) bertujuan untuk memberikan acuan/standar untuk pengembangan tata kelola manajemen aset TI pada Diskominfo Kota Sintang.

Pada tahap selanjutnya menilai kesenjangan antara kematangan saat ini dan kematangan yang diharapkan dapat menggunakan persamaan nilai2

Tingkat kesenjangan $=(\mathrm{x}-\mathrm{y}) \quad(2)$

Keterangan:

$\mathrm{x}=$ Tingkat kematangan saat ini (as-is)

$\mathrm{y}=$ Tingkat kematangan yang diharapkan (tobe).

\subsubsection{IT Asset Manajement (ITAM)}

IT Asset Management (ITAM) atau biasa disebut manajemen aset TI adalah seperangkat proses bisnis yang menyatu dengan bagian keuangan dan inventori dalam mendukung life cycle management dan pengambilan keputusan yang tepat dilingkungan IT. Layanan ITAM dibangun untuk proses melacak data teknis, komersial dan keuangan yang terkait dengan suatu aset. ITAM berfokus pada semua aset yang tersedia pada organisasi seperti software dan 
hardware sebagai sarana untuk proses internal atau sebagai bagian dari layanan. ITAM mencakup seluruh siklus kehidupan aset [8].

\subsubsection{IS Design Science Research}

Information System (IS) design science research atau biasa lebih dikenal dengan Framework Hevner merupakan kerangka kerja yang digunakan dalam penelitian information system (IS). Framework hevner merupakan kerangka kerja konseptual yang digunakan untuk memahami, mengeksekusi dan mengevaluasi penelitian IS yang menggabungkan behavioral-science dan design-science paradigms. Terdapat tiga komponen didalamnya yakni Environment, IS Research dan Knowledge Base. Environment mendefinisikan ruang permasalahan, yang mana didalamnya ada tujuan, tugas, masalah dan peluang yang mendefinisikan kebutuahan bisnis sebagaimana dirasakan oleh stakeholder dalam organisasi. IS Research mendefinisikan tahapan-tahapan yang dilakukan dalam penelitian. Sedangkan Knowledge Base merupakan dasar pengetahuan serta metodologi yang digunakan dalam penelitian. Ketiga komponen ini harus saling mendukung, yang mana komponen dalam environment harus relevan dengan IS research dan komponen knowledge base harus rigor terhadap IS research [9].

\subsection{Tinjauan Pustaka}

Tinjauan pustaka merupakan kumpulan penelitian terdahulu yang digunakan sebagai acuan dalam melakukan penelitian. Adapun tinjauan pustaka pada penelitian ini yakni

Penelitian dengan judul Audit Sistem Informasi Manajemen Aset Berdasarkan Perspektif Proses Bisnis Internal Balance Scorecard dan Standard COBIT 4.1, Model Penilaian Risiko Aset Teknologi Informasi Menggunakan ISO 31000 dan
ISO/IEC 27001 dan Pengelolaan Risiko Aset TI pada Perusahaan Property PT. XYZ Tanggerang Berdasarkan Kerangka Kerja COBIT 4.1.

Penelitian terdahulu berfokus mengukur seberapa jauh keselarasan antara proses bisnis, aplikasi,strategi bisnis perusahaanserta pengelolaan resiko dengan menggunakan standar COBIT 4.1, Balance Scorecard dan ISO/IEC. Sedangkan penelitian yang penulis lakukan berfokus pada Tata Kelola Manajemen Aset TI dengan menggunakan kerangka kerja COBIT 5 dan ITAM.

\section{METODE PENELITIAN}

Metodologi yang digunakan dalam penelitian ini menggunakan kerangka penelitian IS Research [9]. Penelitian sistem informasi harus memiliki dua sisi yang relevan antara pengetahuan dan lingkungan. Teknik yang digunakan dalam penelitian ini bisa dengan melakukan observasi secara langsung, menggunakan kuesioner dan melakukan wawancara. Adapun metodologi atau kerangka penelitian yang digunakan yakni seperti pada gambar 2 . 


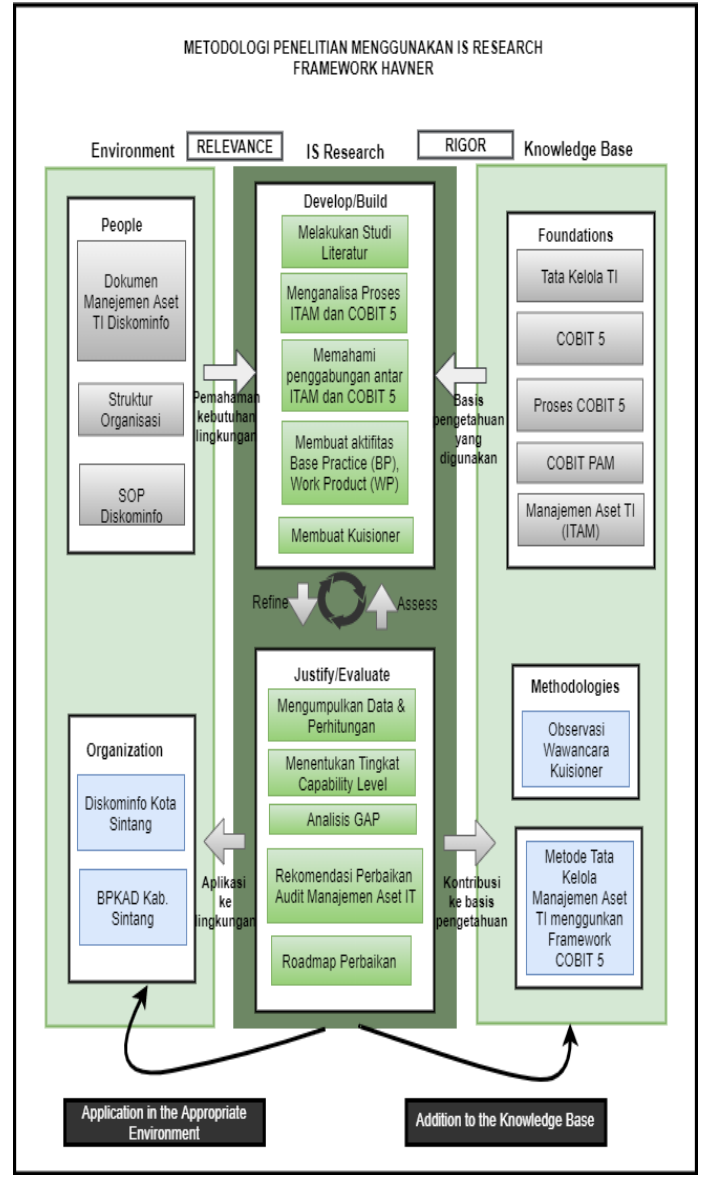

Gambar 2. Kerangka Penelitian

Adapun tahapan kegiatan dalam melakukan Tata Kelola Manajemen Aset TI Menggunakan framework COBIT 5 dan ITAM pada Diskominfo Kota Sintang yaitu dimulai dari melakukan studi literatur baik itu dari sudut environment ataupun sudut knowledge base. Kemudian menganalisa proses ITAM dan COBIT 5, serta memahami proses pengabungan antara ITAM dengan framework COBIT 5. Menentukan siklus hidup manajemen aset TI dari hasil analisa proses pada manajemen aset TI, serta memetakan keterkaitan antara siklus hidup manajemen aset TI dengan framework COBIT 5. Menentukan domain terkait manajemen aset TI. kemudian dibuat keterkaitan antara siklus hidup manajemen aset TI dan domain COBIT 5. Tahap selanjutnya yaitu membuat aktifitas BP (Base Practic) yang terdiri dari aktivitas manajemen aset TI dan WP (Work Product) berupa produk atau dokumen yang berhubungan dengan manajemen aset TI, GP (Generic Practice) dan GWP (Generic Work Product) apabila berhasil mencapai level 2 hingga level 5.Tahap selanjutnya membuat kuisioner capability level berdasarkan BP, WP, GP dan GWP yang akan diajukan ke Diskominfo Kota Sintang. Selanjutnya melakukan audit manajemen aset TI dengan memberikan kuisioner kepada pihak yang terkait dan melakukan peninjauan terhadap ketersediaan dokumen yang telah ditentukan kuisioner Diskominfo Kota Sintang. Menentukan capability level dengan melakukan perhitungan menggunakan analisis GAP. Tahap terakhir memberikan rekomendasi perbaikan yang harus dilakukan Diskominfo Kota Sintang untuk meningkatkan level kematangan.

\section{ANALISIS DAN PERANCANGAN}

\subsection{Siklus Hidup Manajemen Aset TI}

IT Asset Management (ITAM) atau manajemen aset IT adalah proses yang menggabungkan penggunaan dan pemeliharaan aset yang efektif melalui siklus hidupnya untuk memastikan perencanaan yang tepat, pengadaan, perlindungan, upgrade, penggantian dan pembuangan, serta harus memasukkan prosedur yang efektif untuk setiap tahap siklus hidup aset.

Berikut tabel 2 menjelaskan perbandingan siklus hidup IT aset manajemen berdasarkan uraian pendapat dari para penulis:

Tabel 2. PerbandinganSiklus Hidup Manajemen Aset TI

\begin{tabular}{|c|c|c|c|c|c|c|c|c|c|c|}
\hline \multirow{2}{*}{$\begin{array}{l}\text { Nama } \\
\text { Penulis }\end{array}$} & \multicolumn{10}{|c|}{ IT Asset Management Lifecycle } \\
\hline & Request & Procure & Recieve & Stock & Deploy & $\begin{array}{c}\text { Monitor } \\
\text { /Mainta } \\
\text { in }\end{array}$ & Support & IMAC & $\begin{array}{l}\text { Retire/ } \\
\text { Reuse }\end{array}$ & Dispose \\
\hline & $\checkmark$ & $\checkmark$ & $\checkmark$ & v & v & $\checkmark$ & $\checkmark$ & $\checkmark$ & $\checkmark$ & $\checkmark$ \\
\hline \multirow[t]{2}{*}{$\begin{array}{c}\text { (Smith, } \\
\text { 2016) }\end{array}$} & $\sqrt{ }$ & $\checkmark$ & & & $\checkmark$ & $\checkmark$ & & & $\checkmark$ & $\checkmark$ \\
\hline & $\checkmark$ & $\checkmark$ & & & v & $\checkmark$ & & & $\checkmark$ & \\
\hline
\end{tabular}

Berdasarkan hasil analisis siklus hidup aset maka dihasilkan 7 siklus hidup manajemen aset TI, yakni siklus request, procurement, 
receive, deploy, monitor/maintain, retire/reuse dan disposal.

a. Request (permintaan), merupakan proses dimana dilakukannya permintaan terhadap aset TI, didalam suatu organisasi biasanya proses permintaan adalah proses dimana dibuat laporan perencanaan terhadap kebutuhan aset dan penganggaran untuk diajukan kepada bagian terkait terlebih dahulu sebelum dilakukannya pengadaan.

b. Procure (pengadaan), merupakan proses yang dilakukan setelah permintaan disetujui untuk diadakan, pengadaan barang dilaksanakan berdasarkan prinsip efisien, efektif, transparan dan terbuka, bersaing, adil dan akuntabel. Artinya adalah proses pengadaan akan dilakukan apabila sudah mendapat persetujuan dari pemangku kepentingan dan proses pengadaaan akan dilakukan berdasarkan prosedur yang telah ditetapkan.

c. Receive (terima), merupakan proses penentuan untuk penerimaan aset yang sudah diadakan. Proses ini bertujuan agar aset yang sudah diadakan dapat diterima dengan cara yang tepat dan efisien.

d. Deploy (penyebaran), merupakan proses dimana aset TI yang sudah diterima disebarkan untuk di tempatkan pada bidang terkait yang membutuhkan. Pada tahapan ini aset TI sudah masuk pada proses operasional.

e. Monitor/Maintenance, merupakan proses dimana dilakukan pemeriksaan secara fisikterhadap aset, serta memelihara aset yang ada, dengan cara melakukan pengecekan terhadap aset perangkat keras, melakukan proses audit aset atau pun melakukan penginstalan secara rutin terhadap aset perangkat lunak. Alasan tidak menggunakan siklus IMAC dikarenakan siklus tersebut sama hal nya dengan proses maintenance, dimana dilakukannya proses pengiinstalan, pemindahan dan lain sebagainya yang merupakan proses dimana aset diperiksa dan dipelihara. f. Retire/Reuse, merupakan tahapan dimana aset TI sudah mencapai batas akhir penggunaan, perlu diambil tindakan khusus untuk aset-aset TI, terdapat beberapa tindakan yang dapat dilakukan pada aset yaitu penggunaan kembali, hibah atau pembuangan aset.

g. Disposal, merupakan tahapan dimana aset TI sudah benar benar rusak dan tidak dapat digunakan kembali ataupun dihibahkan, sehinggga organisasi harus melakukan pembuangan terhadap aset yang mereka miliki. Pembuangan dapat dilakukan dengan berbagai cara seperti pembakaran, penenggelaman ataupun penghancuran.

\section{PENILAIAN TATA KELOLA}

\subsection{Kuisioner Tata Kelola}

Contoh kuisioner yang digunakan pada saat melakukan proses audit tata kelola dapat dilihat pada tabel 3 .

Tabel 3. Kuisioner Tata Kelola

\begin{tabular}{|c|c|c|c|c|}
\hline NO & KODE & PERTANYAAN & YA & TIDAK \\
\hline 1 & $\begin{array}{l}\text { WP01- } \\
02\end{array}$ & $\begin{array}{l}\text { Apakah ada dokumen } \\
\text { daftar aset yang dimiliki? }\end{array}$ & & \\
\hline 2 & $\begin{array}{l}\text { BP01- } \\
01\end{array}$ & $\begin{array}{l}\text { Apakah dilakukan } \\
\text { identifikasi terhadap } \\
\text { semua aset TI yang } \\
\text { dimiliki dalam daftar aset } \\
\text { serta dilakukan } \\
\text { pencatatan status aset saat } \\
\text { ini? }\end{array}$ & & \\
\hline 3 & $\begin{array}{l}\text { BP01- } \\
\text { 02 }\end{array}$ & $\begin{array}{l}\text { Apakah dilakukan } \\
\text { identifikasi terhadap } \\
\text { persyaratan hukum, } \\
\text { peraturan, atau kontrak } \\
\text { yang perlu ditangani } \\
\text { ketika mengelola aset TI? }\end{array}$ & & \\
\hline 4 & $\begin{array}{l}\text { WP01- } \\
03\end{array}$ & $\begin{array}{l}\text { Apakah ada dokumen } \\
\text { hasil pemeriksaan fisik } \\
\text { aset TI ? }\end{array}$ & & \\
\hline 5 & $\begin{array}{l}\text { WP01- } \\
06\end{array}$ & $\begin{array}{l}\text { Apakah ada dokumen } \\
\text { laporan hasil pengukuran } \\
\text { terkait manajemen aset } \\
\text { TI? }\end{array}$ & & \\
\hline 6 & $\begin{array}{l}\text { BP01- } \\
\text { 07 }\end{array}$ & $\begin{array}{l}\text { Apakah adanya } \\
\text { identifikasi terkait risiko, } \\
\text { biaya, dan implikasi dari } \\
\text { perubahan organisasi, } \\
\text { perkembangan teknologi, } \\
\text { persyaratan peraturan, } \\
\text { rekayasa ulang proses } \\
\text { bisnis, kepegawaian, } \\
\text { peluang insourching dan } \\
\text { outsourcing, dalam proses } \\
\text { perencanaan? }\end{array}$ & & \\
\hline 7 & $\begin{array}{l}\text { BP01- } \\
08\end{array}$ & $\begin{array}{l}\text { Apakah perusahaan } \\
\text { membuat matriks dan } \\
\text { target dengan } \\
\text { penyelarasan antara } \\
\text { tujuan dengan ukuran } \\
\text { hasil yang dapat dikaitkan }\end{array}$ & & \\
\hline
\end{tabular}




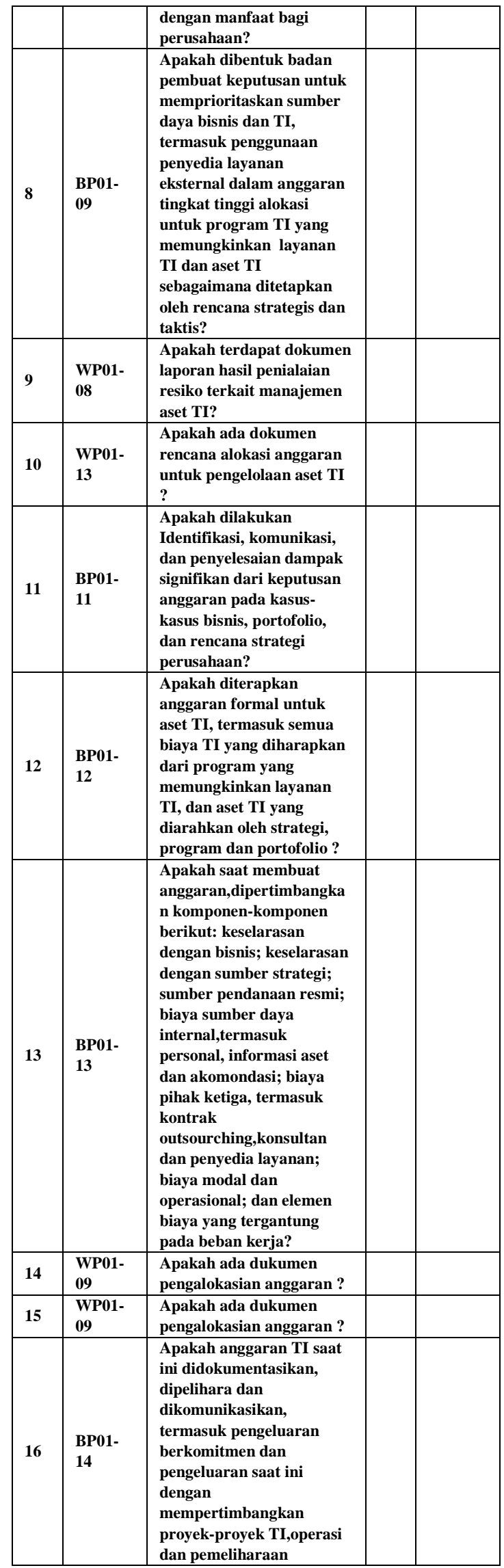

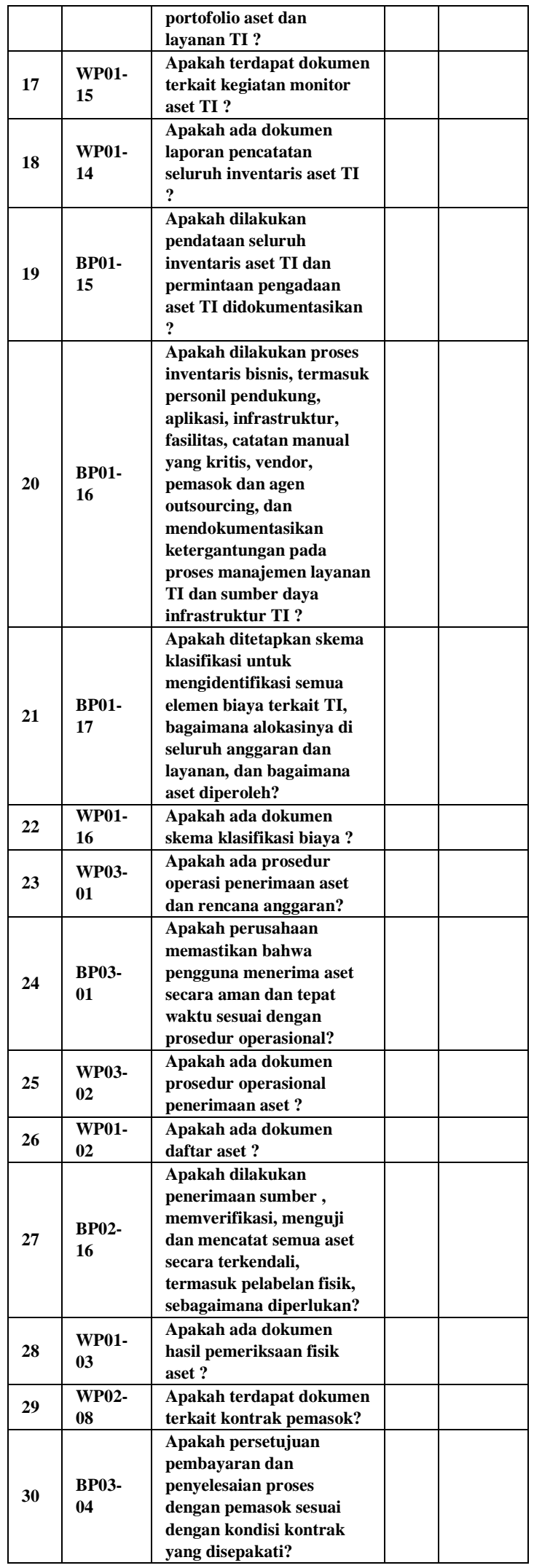

\subsection{Pengukuran Tingkat Kematangan}


Setelah dilakukan studi kasus tepatnya 12 september 2019 pada Diskominfo dengan menyebarkan kuisioner tata kelola kepada stakeholder yang terkaitdiantaranya Bapak Rosandri Chandra, SP,ME selaku Plt.Sekretaris Diskominfo, Bapak Wisnarto A.MD selaku Kasubag Keuangan, Program dan Perlengkapan, Ibu Renipuji Lestari, S.Sos, S.Ak selaku Staf Keuangan, Program dan Perlengkapan dan Bapak Fenny Parwandi, S.Kom selaku Kasi Pengelolaan Data dan Informasi Pembangunan, maka selanjutnya dilakukan perhitungan atau pengukuran tingkat kematangan disetiap proses dimulai dari level 0 seperti pada tabel 4. Adapun pengukuran tingkat kematangan manajemen aset TI pada tabel 4 berikut.

Tabel 4. Pengukuran Tingkat Kematangan Level 0

\begin{tabular}{|c|c|c|c|c|c|c|c|c|c|}
\hline No & Proses & $\begin{array}{l}\text { L } \\
\text { e } \\
\text { v } \\
\text { e }\end{array}$ & & \multicolumn{2}{|c|}{$\begin{array}{c}\text { Jumlah } \\
\text { Pertanya } \\
\text { an }\end{array}$} & Ya & $\begin{array}{l}\text { Tid } \\
\text { ak }\end{array}$ & $\begin{array}{l}\text { Jum } \\
\text { lah }\end{array}$ & $\begin{array}{c}\text { Skala } \\
\text { Penguku } \\
\text { ran }\end{array}$ \\
\hline \multirow[b]{2}{*}{1} & \multirow{2}{*}{$\begin{array}{c}\text { Siklus } \\
\text { Reque } \\
\text { st }\end{array}$} & & BP & 17 & \multirow{2}{*}{$\begin{array}{l}3 \\
2\end{array}$} & 8 & 9 & \multirow{2}{*}{$\begin{array}{l}46 \\
\%\end{array}$} & \multirow{2}{*}{$\begin{array}{l}\mathbf{P}(\mathbf{1 5 \%} \text { - } \\
\mathbf{5 0 \% )}\end{array}$} \\
\hline & & & WP & 15 & & 7 & 8 & & \\
\hline \multirow{2}{*}{2} & \multirow{2}{*}{$\begin{array}{c}\text { Siklus } \\
\text { Procur } \\
\text { ement }\end{array}$} & & BP & 22 & \multirow{2}{*}{$\begin{array}{l}4 \\
0\end{array}$} & 17 & 5 & \multirow{2}{*}{$\begin{array}{l}65 \\
\%\end{array}$} & \multirow{2}{*}{$\begin{array}{l}\text { L(50\% - } \\
85 \%)\end{array}$} \\
\hline & & & WP & 18 & & 9 & 9 & & \\
\hline \multirow[b]{2}{*}{3} & \multirow{2}{*}{$\begin{array}{c}\text { Siklus } \\
\text { Receiv } \\
e\end{array}$} & & BP & 4 & \multirow[b]{2}{*}{$\begin{array}{l}\mathbf{1} \\
\mathbf{0}\end{array}$} & 4 & $\mathbf{0}$ & \multirow{2}{*}{$\begin{array}{l}90 \\
\%\end{array}$} & \multirow{2}{*}{$\begin{array}{l}\mathbf{F}(85 \% \text { - } \\
100 \%)\end{array}$} \\
\hline & & & WP & 6 & & 5 & 1 & & \\
\hline \multirow{2}{*}{4} & \multirow{2}{*}{$\begin{array}{c}\text { Siklus } \\
\text { Deploy }\end{array}$} & & BP & 4 & \multirow{2}{*}{8} & $\mathbf{0}$ & 4 & \multirow{2}{*}{$\begin{array}{l}12 \\
\%\end{array}$} & \multirow{2}{*}{$\begin{array}{l}\mathbf{P}(15 \%- \\
\mathbf{5 0 \%})\end{array}$} \\
\hline & & o & WP & 4 & & 1 & 3 & & \\
\hline \multirow[b]{2}{*}{5} & \multirow{2}{*}{$\begin{array}{c}\text { Siklus } \\
\text { Monit } \\
\text { or/Mai } \\
\text { ntain }\end{array}$} & & BP & 11 & \multirow[b]{2}{*}{$\begin{array}{l}1 \\
6\end{array}$} & 9 & 2 & \multirow[b]{2}{*}{$\begin{array}{l}68 \\
\%\end{array}$} & \multirow[b]{2}{*}{$\begin{array}{l}\text { L(50\% - } \\
85 \%)\end{array}$} \\
\hline & & & WP & 5 & & 3 & 2 & & \\
\hline \multirow[b]{2}{*}{6} & \multirow{2}{*}{$\begin{array}{l}\text { Siklus } \\
\text { Retire/ } \\
\text { Reuse }\end{array}$} & & BP & 8 & \multirow{2}{*}{$\begin{array}{l}1 \\
6\end{array}$} & 6 & 2 & \multirow{2}{*}{$\begin{array}{l}55 \\
\%\end{array}$} & \multirow{2}{*}{$\begin{array}{l}\text { L }(50 \% \text { - } \\
85 \%)\end{array}$} \\
\hline & & & WP & 8 & & 3 & 5 & & \\
\hline \multirow[b]{2}{*}{7} & \multirow{2}{*}{$\begin{array}{c}\text { Siklus } \\
\text { Dispos } \\
\text { al }\end{array}$} & & BP & 5 & \multirow[b]{2}{*}{$\begin{array}{l}1 \\
1\end{array}$} & 3 & 2 & \multirow{2}{*}{$\begin{array}{l}63 \\
\%\end{array}$} & \multirow{2}{*}{$\begin{array}{l}\text { L }(50 \% \text { - } \\
85 \%)\end{array}$} \\
\hline & & & WP & 6 & & 4 & 2 & & \\
\hline
\end{tabular}

Setelah didapat pengukuran pada level 0 , dilihat kembali untuk pengukuran level 1 dan yang dapat masuk kedalam level 1 yakni yang memiliki nilai skala pengukuran L (50\% $85 \%)$ atau F (85\% - 100\%). Dari tabel 5.1 dapat dilihat bahwa siklus receive dan deploy memiliki nilai skala pengukuran $\mathrm{P}(15 \%$ $50 \%$ ) sehingga masih berada di level 0.

Setelah diketahui proses yang ada di level 1 selanjutnya dapat dilihat kembali apakah proses tersebut dapat naik ke level 2 atau tidak. Untuk naik ke level 2 proses PA 1.1 harus mencapai nilai skala pengukuran $\mathrm{F}$ $(85 \%$ - 100\%) dan PA2.1 dan PA 2.2 memiliki nilai skala pengukuran L (50\% -
$85 \%$ ) atau F (85\% - 100\%). Adapun tabel pengukuran dapat dilihat pada tabel 5 berikut.

Tabel 5. Pengukuran Tingkat Kematangan Level PA1.1

\begin{tabular}{|c|c|c|c|c|c|c|c|c|c|}
\hline No & $\begin{array}{c}\text { Prose } \\
\text { s }\end{array}$ & $\begin{array}{l}\text { Le } \\
\text { vel }\end{array}$ & & \multicolumn{2}{|c|}{$\begin{array}{c}\text { Jumlah } \\
\text { Pertanya } \\
\text { an }\end{array}$} & Ya & $\begin{array}{c}\text { Tid } \\
\text { ak }\end{array}$ & $\begin{array}{l}\text { Jum } \\
\text { lah }\end{array}$ & $\begin{array}{l}\text { Skala } \\
\text { Pengu } \\
\text { kuran }\end{array}$ \\
\hline \multirow{2}{*}{1} & \multirow{2}{*}{$\begin{array}{c}\text { Siklus } \\
\text { Procu } \\
\text { remen } \\
t\end{array}$} & \multirow{10}{*}{$\begin{array}{c}\text { P } \\
\text { A1 } \\
.1\end{array}$} & $\begin{array}{l}\text { B } \\
\text { P }\end{array}$ & 22 & 4 & 17 & 5 & 65 & $\mathbf{L}(50$ \\
\hline & & & $\begin{array}{l}W \\
P\end{array}$ & 18 & 0 & 9 & 9 & $\%$ & $85 \%)$ \\
\hline \multirow{2}{*}{2} & \multirow{2}{*}{$\begin{array}{l}\text { Siklus } \\
\text { Receiv } \\
\quad e\end{array}$} & & $\begin{array}{l}\text { B } \\
\text { P }\end{array}$ & 4 & \multirow{2}{*}{$\begin{array}{l}1 \\
0\end{array}$} & 4 & 0 & \multirow{2}{*}{$\begin{array}{l}90 \\
\%\end{array}$} & \multirow{2}{*}{$\begin{array}{l}\mathbf{F}(85 \\
\%- \\
100 \% \\
)\end{array}$} \\
\hline & & & $\begin{array}{l}\text { W } \\
\mathbf{P} \\
\end{array}$ & 6 & & 5 & 1 & & \\
\hline \multirow{2}{*}{3} & \multirow{2}{*}{$\begin{array}{l}\text { Siklus } \\
\text { Monit } \\
\text { or/Ma } \\
\text { intain }\end{array}$} & & $\begin{array}{l}\mathbf{B} \\
\mathbf{P}\end{array}$ & 11 & \multirow{2}{*}{$\begin{array}{l}1 \\
6\end{array}$} & 9 & 2 & \multirow{2}{*}{$\begin{array}{l}68 \\
\%\end{array}$} & \multirow{2}{*}{$\begin{array}{l}\text { L(50 } \\
\%- \\
85 \%)\end{array}$} \\
\hline & & & $\begin{array}{l}W \\
P\end{array}$ & 5 & & 3 & 2 & & \\
\hline \multirow{2}{*}{4} & \multirow{2}{*}{$\begin{array}{c}\text { Siklus } \\
\text { Retire } \\
\text { /Reus } \\
e \\
\end{array}$} & & $\begin{array}{l}\text { B } \\
\text { P }\end{array}$ & 8 & \multirow{2}{*}{$\begin{array}{l}1 \\
6\end{array}$} & 6 & 2 & \multirow{2}{*}{$\begin{array}{l}55 \\
\%\end{array}$} & \multirow{2}{*}{$\begin{array}{l}\text { L(50) } \\
\%- \\
85 \%)\end{array}$} \\
\hline & & & $\begin{array}{l}\text { W } \\
\mathbf{P}\end{array}$ & 8 & & 3 & 5 & & \\
\hline \multirow{2}{*}{5} & \multirow{2}{*}{$\begin{array}{c}\text { Siklus } \\
\text { Dispo } \\
\text { sal }\end{array}$} & & $\begin{array}{l}\text { B } \\
\mathbf{P}\end{array}$ & 5 & \multirow{2}{*}{$\begin{array}{l}1 \\
1\end{array}$} & 3 & 2 & \multirow{2}{*}{$\begin{array}{l}63 \\
\%\end{array}$} & \multirow{2}{*}{$\begin{array}{l}\mathbf{L}(50 \\
\%- \\
85 \%)\end{array}$} \\
\hline & & & $\begin{array}{l}\text { W } \\
\mathbf{P}\end{array}$ & 6 & & 4 & 2 & & \\
\hline
\end{tabular}

Dari tebel 5 diketahui bahwa hanya siklus receive yang memiliki nilai $\mathrm{F}(85 \%-100 \%)$, sehingga proses tersebut dapat dilakukan penilaian kembali dengan menggunakan PA 2.1 dan PA 2.2 untuk memastikan best practice dan work product di kelola dengan baik dan benar. Adapun tabel pengukuran dapat dilihat pada tabel 6 sebagai berikut.

Tabel 6. Pengukuran Tingkat Kematangan PA 2.1 dan PA 2.2

\begin{tabular}{|c|c|c|c|c|c|c|c|c|}
\hline No & $\begin{array}{c}\text { Pros } \\
\text { es }\end{array}$ & $\begin{array}{l}\text { Le } \\
\text { vel }\end{array}$ & & $\begin{array}{c}\text { Juml } \\
\text { ah } \\
\text { Perta } \\
\text { nyaa } \\
\text { n }\end{array}$ & Ya & $\begin{array}{c}\text { Tida } \\
\text { k }\end{array}$ & $\begin{array}{c}\text { Juml } \\
\text { ah }\end{array}$ & $\begin{array}{c}\text { Skala } \\
\text { Pengu } \\
\text { kuran }\end{array}$ \\
\hline \multirow{2}{*}{1} & \multirow{2}{*}{$\begin{array}{c}\text { Siklu } \\
\text { s } \\
\text { Recei } \\
v e\end{array}$} & $\begin{array}{l}\text { PA } \\
2.1\end{array}$ & GP & 6 & 4 & 2 & $66 \%$ & $\begin{array}{c}\mathbf{L} \\
(50 \%- \\
85 \%)\end{array}$ \\
\hline & & $\begin{array}{l}\text { PA } \\
2.2\end{array}$ & $\begin{array}{l}\mathbf{G} \\
\mathbf{W} \\
\mathbf{P}\end{array}$ & 4 & 1 & 3 & $25 \%$ & $\begin{array}{l}\mathbf{P}(\mathbf{1 5 \%} \\
-\mathbf{5 0} \%)\end{array}$ \\
\hline
\end{tabular}

Dari hasil pengukuran tersebut dapat diketahui bahwa proses pada siklus receive pada manajemen aset IT belum berhasil mencapai ke level 2 karena untuk mencapai level 2 PA2.1 dan PA2.2 harus memiliki nilai skala pengukuran $\mathrm{L}(50 \%-85 \%)$ atau $\mathrm{F}(85 \%-100 \%)$.

\subsection{Analisis GAP}

Berdasarkan pengukuran didapat tingkat kematangan atau level untuk saat ini dari setiap proses. Dari hasil pengukuran tersebut dapat dilakukan analisis gap untuk mengetahui kesenjangan antara tingkat 
kematangan saat ini dan tingkat kematangan yang diharapkan. Nilai kematangan yang diharapkan oleh pihak Diskominfo yakni 1 tingkat diatas level saat ini. Adapun hasil analisis GAP dapat dilihat pada tabel 7sebagai berikut.

Tabel 7. Analisis GAP

\begin{tabular}{|l|l|c|c|c|}
\hline No & Proses & $\begin{array}{l}\text { Level } \\
\text { Saat } \\
\text { ini }\end{array}$ & Harapan & GAP \\
\hline 1 & Siklus Request & 0 & 1 & -1 \\
\hline 2 & Siklus Procurement & 1 & 2 & -1 \\
\hline 3 & Siklus Receive & 1 & 2 & -1 \\
\hline 4 & Siklus Deploy & 0 & 1 & -1 \\
\hline 5 & $\begin{array}{l}\text { Siklus } \\
\text { Monitor/Maintain }\end{array}$ & 1 & 2 & -1 \\
\hline 6 & Siklus Retire/Reuse & 1 & 2 & -1 \\
\hline 7 & Siklus Disposal & 1 & 2 & -1 \\
\hline
\end{tabular}

\subsection{Rekomendasi Perbaikan}

Dari hasil analisis yang telah dilakukan sebelumnya didapat rekomendasi perbaikan untuk mencapai level yang sesuai dengan harapan instansi yakni 1 tingkat diatas level saat ini. Adapun rekomendasi untuk setiap level atau proses atribut yakni :

1. Rekomendasi untuk level 0 pada siklus receive dan deploy, sebagai berikut:

a. Melakukan pendataan berupa daftar inventaris aset untuk jenis aset hardware, software dan aset information

b. Perlu adanya pembaharuan repository aset terhadap setiap perubahan yang berkaitan dengan aset TI

c. Melakukan penyebaran atau penempatan aset TI berdasarkan prosedur panduan penyebaran aset $\mathrm{TI}$

d. Dibuatnya standar operasional prosedur untuk penyebaran aset TI

e. Didalam proses penyebaran aset seharusnya dilakukan proses penandatanganan sebagai bukti dan tanggung jawab penerima aset TI

f. Melakukan pembaharuan repository aset berdasarkan setiap penyebaran yang dilakukan

g. Mendokumentasikan setiap proses penyebaran aset TI yang dilakukan

2. Rekomendasi untuk PA1.1 pada siklus procurement, receive, monitor/maintain, retire/reuse dan disposal, sebagai berikut: a. Perlu dilakukan pengukuran terhadap manajemen aset TI yang sudah ada saat ini

b. Perlu adanya dokumen laporan hasil pengukuran terkait manajemen aset TI

c. Perlu adanya pembaharuan repository aset terhadap setiap perubahan yang berkaitan dengan aset TI

d. Perlu adanya identifikasi terkait risiko, biaya dan perkembangan teknologi dalam proses perencanaan aset TI

e. Perlu adanya kegiatan monitor terkait manajemen aset TI, serta rencana perawatan terhadap aset TI harus diimplementasikan

f. Membuat dokumen terkait perjanjian pemeliharaan aset TI

g. Melakukan pengkomunikasian rencana perawatan aset TI dengan bidang terkait

h. Membuat dokumen prosedur untuk pemusnahan data, software dan hardware

i. Mendokumentasikan setiap kegiatan dalam manajemen aset TI mulai dari proses perencanaan hingga pemusnahaan aset, dengan tujuan agar setiap tindakan yang dilakukan dalam pengelolaan aset TI terdokumentasi dengan jelas

j. Untuk naik ke level 2 semua best practice dan work product disetiap proses pada PA1.1 harus dilaksanakan dan lengkap.

3. Rekomendasi untuk PA2.1 dan PA2.2 pada siklus receive, sebagai berikut:

a. Membuat dokumen terkait identifikasi strategi pada kegiatan penerimaan aset dalam manajemen aset TI

b. Membuat dokumen laporan terkait pemantauan pada kegiatan penerimaan aset TI dalam manajemen aset TI

c. Membuat dokumen peninjauan terkait kegiatan penerimaan aset TI, yang dapat digunakan sebagai evaluasi kedepannya

d. Dokumentasikan setiap kegiatan penerimaan aset TI yang dilakukan

\section{KESIMPULAN}

Berdasarkan pembahasan pada bab sebelumnya, dapat ditarik kesimpulan bahwa:

1. Proses manajemen aset TI pada penelitian ini didapat dari siklus hidup manajemen aset TI yang telah didefinisikan oleh para 
peneliti terdahulu, sehingga menghasilkan tujuh proses dalam manajemen aset TI yakni proses request, procurement, receive, deploy, monitor/maintain, retire/reuse dan disposal yang kemudian disesuaikan dengan COBIT 5 untuk menghasilkan BP (Best Practice) dan WP (Work Product). Dan untuk level 2 hingga level 5 disesuaikan dengan GP (Generic Practice) dan GWP (Generic Work Product).

2. Tingkat kematangan berdasarkan skala pengukuran COBIT PAM pada Dinas Komunikasi dan Informatika Kota Sintang pada proses request dan deploy aset masih berada di level 0 . Sedangkan tingkat kematangan pada proses procurement, receive, monitor/maintain,retire/reuse dan disposal berada di level 1.

3. Secara keseluruhan Dinas Komunikasi dan Informatika Kota Sintang sudah memiliki kesadaran tata kelola yang baik mulai dari memiliki visi dan misi yang jelas, memiliki tugas dan fungsi yang jelas sesuai dengan struktur organisasi, memiliki standar operasional prosedur dalam pengadaan aset TI dan kegiatan pengelolaan aset TI secara keseluruhan telah dilakukan sesuai dengan Peraturan yang telah ditetapkan oleh Bupati, yakni tertuang dalam Peraturan Daerah Kabupaten Sintang N0.1 tahun 2017 tentang Pengelolaan Barang Milik Daerah, Peraturan Bupati Sintang No 44 tahun 2018 tentang Standar Harga Satuan Barang dan Jasa Kebutuhan Pemerintah Kabupaten Sintang Tahun Anggaran 2018, Peraturan Bupati Sintang No 77 tahun 2017 tentang Tata Cara Pelaksanaan Pemindahtanganan Barang Milik Daerah, dan Peraturan Bupati Sintang tentang Tata Cara Pelaksanaan Pemusnahan dan Penghapusan Barang Milik Daerah di Lingkungan Kabupaten Sintang. Namun masih perlu dilakukan proses dokumentasi terkait proses manajemen aset TI.

4. Proses manajemen Aset TI pada penelitian ini juga dapat menjadi pengetahuan tambahan bagi bidang keilmuan sistem informasi khususnya. Karena ada beberapa proses aktifitas didalam manajemen aset TI yang tidak terdapat didalam kerangka kerja COBIT 5.

\section{SARAN}

Berdasarkan kesimpulan maka berikut saran yang tepat untuk peningkatan kinerja Diskominfo Kota Sintang khususnya dalam Tata Kelola Manajemen Aset TI. Adapun saran yang diberikan antara lain:

1. Melakukan dokumentasi pada setiap proses sesuai dengan pedoman tata kelola manajemen aset TI

2. Mengimplementasikan setiap rekomendasi yang diberikan untuk meningkatkan level kematangan pada proses tata kelola manajemen aset TI

3. Melakukan pengkomunikasian kepada semua stakeholder terkait setiap pengambilan keputusan

4. Membuat sistem tata kelola sesuai dengan kerangka penelitian ini sehingga mempermudah dalam melakukan audit maupun proses tata kelola manajemen aset TI

5. Menggunakan manajemen aset TI sebagai pengetahuan tambahan dalam melakukan tata kelola terkait aset TI.

\section{DAFTAR PUSTAKA}

[1] Guldentops, E. (2004). IT Governance Frameworks. Dalam S. D. Wim Van Grembergen, \& J. T. Mehdi Khosrow-Pour (Penyunt.), IT Governance Frameworks (hal. 54). USA, USA, United States of America \& United Kingdom: IDEA GROUP PUBLISHING. Dipetik November 25, 2018 , dari http://www.idea-group.com, http://www.eurospan.co.uk

[2] Thomas. (2018). IT Asset Management and COBIT® 5. Retrieved from Strategic ingredients for effective Governance of Enterprise IT: http://wwwwww.apmginternational.com 
[3] ISACA. (2012). COBIT 5 Enabling Processes. Rolling Meadows, IL 60008 USA, United States of America: ISACA. Dipetik November 15, 2018, dari www.isaca.org: http://www.isaca.org

[4] ITGI. (2005). Definitions of IT governance. (J. N. Kristin Klinger, Penyunt.) Implementing Information Technology Governance, 271. Dipetik November 14, 2018, dari http://www.igi-global.com

[5] ISACA.(2012). COBIT 5 A Business Framework for the Governance and Management of Enterprise IT. Rolling Meadows, USA: ISACA.

[6] ISACA. (2012), COBIT Process Assessment Model (PAM). Rolling Meadows, USA: ISACA.

[7] Kotler, Philip.(2002). Manajemen Pemasaran, terjemahan Hendra Teguh, edisi Millinium, cetakan kesepuluh, Prenhalindo, Jakarta.

[8] Sefkey, A. (2003). IT Asset Management (How To Menage Your IT Equipment). London: Great Britain. Diambil kembali dari www.briefingzone.com

[9] Hevner, 2004, Design Science in Information Systems Research. Management Information Systems Quarterly, 77-105. 